Novel polycarbonate-graphene nanocomposite foams prepared by $\mathrm{CO}_{2}$ dissolution

This article has been downloaded from IOPscience. Please scroll down to see the full text article.

2012 IOP Conf. Ser.: Mater. Sci. Eng. 31012008

(http://iopscience.iop.org/1757-899X/31/1/012008)

View the table of contents for this issue, or go to the journal homepage for more

Download details:

IP Address: 147.83.83.97

The article was downloaded on 17/05/2013 at 15:14

Please note that terms and conditions apply. 


\title{
Novel polycarbonate-graphene nanocomposite foams prepared by $\mathrm{CO}_{2}$ dissolution
}

\author{
G Gedler, M Antunes, V Realinho and J I Velasco ${ }^{1}$ \\ Centre Català del Plàstic. Departament de Ciència dels Materials i Enginyeria \\ Metal-lúrgica. Universitat Politècnica de Catalunya, C/Colom 114. E-08222 Terrassa, \\ Barcelona, Spain. \\ ${ }^{1}$ E-mail: jose.ignacio.velasco@upc.edu
}

\begin{abstract}
Polycarbonate foams reinforced with $0,5 \mathrm{wt} \%$ of graphene were obtained by firstly melt-mixing the polycarbonate and graphene in an internal mixer, compression-moulding the melt-compounded grinded material and lastly dissolving $\mathrm{CO}_{2}$ inside a high pressure vessel. The $\mathrm{CO}_{2}$ desorption behaviour in the unfilled polycarbonate and nanocomposite was studied in terms of the $\mathrm{CO}_{2}$ saturation concentration and desorption diffusion coefficient, with the graphene-filled nanocomposite displaying a higher $\mathrm{CO}_{2}$ loss rate when compared to the neat polycarbonate. The cellular structure of the foams was found to be highly dependent on the saturation/foaming temperature, with smaller cell sizes being obtained with decreasing the temperature. Another parameter that had an important influence was the residual pressure, with higher residual pressure values resulting in foams with more uniform and regular cells.
\end{abstract}

\section{Introduction}

Polymeric foams are currently used in industrial applications where lightness is a key factor [1]. The final properties of these foams depend on their cellular structure, which includes parameters such as the average cell size and size distribution, cell volume fraction and cell arrangement within the matrix [2]. Nevertheless, the use of polymer foams is somewhat limited due to the inherent reduction of their mechanical properties with foaming when compared to the solid base material. These foams are known for displaying better specific properties when cell sizes are reduced to a micrometer scale, hence having the potential to significantly alter the way plastics are employed in a wide variety of applications [3]. Nowadays the trend lies in improving the specific mechanical response of these socalled microcellular foams and adding functionalities, such as thermal or electrical conduction, considering both the material's composition and cellular structure control [4]. The most common microcellular foaming process uses a physical blowing agent that creates an evenly distributed micrometric-sized closed cell structure, which significantly improves the mechanical properties compared to more heterogeneous or open cell structures [5]. Supercritical carbon dioxide $\left(\mathrm{sc}-\mathrm{CO}_{2}\right)$ is one of the most favorable ones due to its combination of chemical inertness, non-flammability and mild supercritical conditions $\left(T_{\mathrm{c}}=31^{\circ} \mathrm{C}, P_{\mathrm{c}}=7,38 \mathrm{MPa}\right)$ [6], also being environmentally benign [7]. One of the advantages of using physical blowing agents is that cell structure may be controlled through the processing temperature and pressure. Nevertheless, in order to optimize foam properties, an overall understanding of the gas diffusion and the nucleation and growth mechanisms is required [8].

In order to create cells with uniform sizes, all cells must nucleate simultaneously after rapid depressurization. A common approach to this problem considers the use of fillers that act as 
heterogeneous nucleating agents [9]. In addition, and depending on their characteristics, these fillers may also act as nanoreinforcements. Carbon nanotubes and nanofibres have increasingly been used looking not only for mechanical but also for thermal and electrical properties improvements. Graphene nanosheets have currently attracted a great deal of interest due to their high theoretical properties and particular flat morphology [10-11]. Graphene displays high mechanical, thermal and electrical properties suitable for developing conductive nanocomposites, which could be useful in electronic circuits, sensors and actuators [12]. The combination of these properties with fire retardancy could lead to the development of polymer nanocomposites with tailor-made properties [13].

Although graphene-reinforced polymer composites have already been thoroughly studied in the last few years, the knowledge of foams made from these materials is still pretty scarce, mainly due to their multiphase nature, direct result of the combination of a complex developed cellular structure and polymer microstructure [14]. The influence of the foaming conditions has lately been considered, mainly focused in obtaining high performance foams by means of decreasing cell size and incorporating inorganic functional fillers [15].

The purpose of this study was to prepare polycarbonate-graphene foams through a physical sc$\mathrm{CO}_{2}$ one-step batch foaming process and to characterize them in terms of the developed cellular structure morphology.

\section{Experimental}

\subsection{Materials and compounding}

Polycarbonate (Lexan-123R-PC, supplied by Sabic), with a density of $1,2 \mathrm{~g} / \mathrm{cm}^{3}$ and MFI of 17,5 $\mathrm{dg} / \mathrm{min}$, measured at $300{ }^{\circ} \mathrm{C}$ and $1,2 \mathrm{~kg}$, was melt-mixed with $0,5 \mathrm{wt} \%$ of graphene using a Brabender Plasti-Corder internal mixer. The graphene used in this study was supplied by XG Sciences, Inc., USA. These $\mathrm{xGnP}$-Grade-M graphene nanoplatelets are 6 to $8 \mathrm{~nm}$ thick with a $15 \mu \mathrm{m}$ average diameter and a density of $2,2 \mathrm{~g} / \mathrm{cm}^{3}$, as reported by the manufacturer.

Firstly, the PC and graphene were physically mixed and slowly introduced in the internal mixer at a temperature of $180{ }^{\circ} \mathrm{C}$ using a rotating speed of $30 \mathrm{rpm}$ during $2 \mathrm{~min}$. Then the rotating speed was increased to $60 \mathrm{rpm}$ and $120 \mathrm{rpm}$ for 1 and $3 \mathrm{~min}$, respectively. The material was cooled at room temperature, grinded and compression-moulded at $220^{\circ} \mathrm{C}$ and 45 bar in a hot-plate press (IQAP LAP PL-15) to discs with a thickness of 3,5 $\mathrm{mm}$ and diameter of $74 \mathrm{~mm}$ in 3 steps. In the first step the upper hot plate was used to soften the material at a temperature of $220^{\circ} \mathrm{C}$. The second step consisted in allowing air to escape the material by pulsating the upper plate in an up and down motion. The pressure applied from the upper plate was $45 \mathrm{bar}$ at a temperature of $220^{\circ} \mathrm{C}$ during $1,5 \mathrm{~min}$. For the third step the material was continuously compressed for $1 \mathrm{~min}$ at $220^{\circ} \mathrm{C}$ and 45 bar (see Figure 1 for scheme of the compression-moulding process). Lastly, the mould with the sample still inside was left to cool for $15 \mathrm{~min}$ in the cooling station of the press applying a constant pressure of $45 \mathrm{bar}$.

The resulting compression-moulded solid discs were used to prepare the foams by sc- $\mathrm{CO}_{2}$ dissolution, while the discs used in the $\mathrm{CO}_{2}$ desorption measurements were prepared by mechanically reducing the disc diameter to a typical value of $40 \mathrm{~mm}$. 
1.

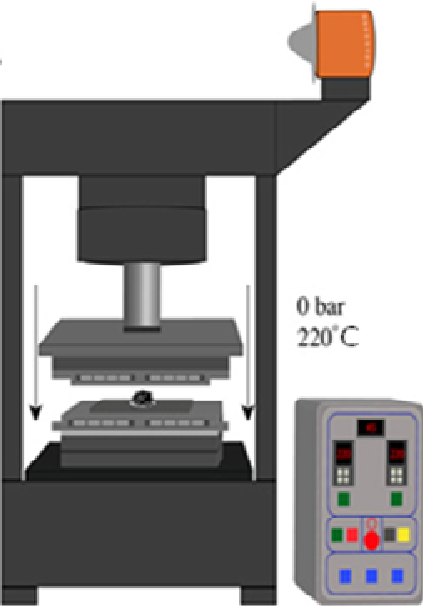

2.

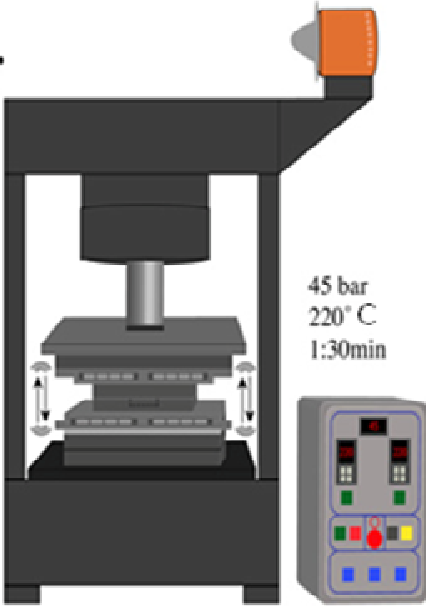

3.

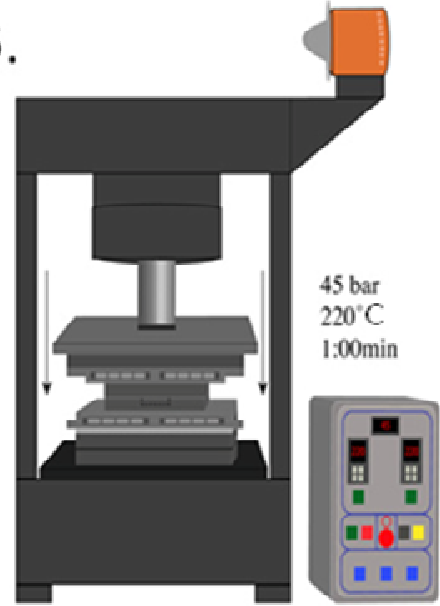

Figure 1. Scheme of the compression-moulding process.

\section{2. $\mathrm{CO}_{2}$ desorption measurements}

In order to determine both the solubility and diffusion coefficient of $\mathrm{CO}_{2}$ in the neat polycarbonate and polycarbonate-graphene nanocomposite, $\mathrm{CO}_{2}$ desorption measurements were carried out. Samples were introduced in the high pressure vessel and heated up to $210^{\circ} \mathrm{C}$ at a $\mathrm{CO}_{2}$ pressure of $160 \mathrm{bar}$. After reaching the saturation conditions, the samples were cooled to $40{ }^{\circ} \mathrm{C}$ and the $\mathrm{CO}_{2}$ fully decompressed. Next, the saturated samples were removed from the vessel and quickly transferred to a digital balance (Mettler Toledo PB303 DeltaRange, with a sensitivity of $1 \mathrm{mg}$ ) at room temperature and atmospheric pressure, in order to record the $\mathrm{CO}_{2}$ mass loss as a function of desorption time.

The maximum concentration of $\mathrm{CO}_{2}$ in the samples after full decompression $\left(M_{0}\right)$ was calculated by extrapolating to zero desorption time using the initial slope method [16]. Assuming onedimensional diffusion in a plane sheet, the $\mathrm{CO}_{2}$ desorption diffusion coefficient $\left(D_{\mathrm{d}}\right)$ was determined by plotting $M_{\mathrm{t}} / M_{0}$ vs. $t / l^{2}$, where $M_{\mathrm{t}}$ is the $\mathrm{CO}_{2}$ concentration at time $t$ and $l$ is the thickness of the sample, according to the following equation [17]:

$$
\frac{M_{t}}{M_{0}}=1-\frac{8}{\pi^{2}} \exp \left(\frac{-D_{\mathrm{d}} t}{l^{2}}\right)
$$

\subsection{Foaming process}

Foams were prepared by a sc- $\mathrm{CO}_{2}$ dissolution one-step batch process that consisted in saturating the solid discs with $\mathrm{CO}_{2}$ inside the high pressure vessel at pressures varying from 120 to 160 bar during time periods between 0 and $120 \mathrm{~min}$. The values of the saturation/foaming temperature varied between 200 and $213{ }^{\circ} \mathrm{C}$, and foaming was done in one-step by applying a sudden pressure drop, keeping residual pressures that ranged between 0 and 20 bar. Figure 2 displays both the $\mathrm{CO}_{2}$ pressurization and depressurization steps used in foaming. 

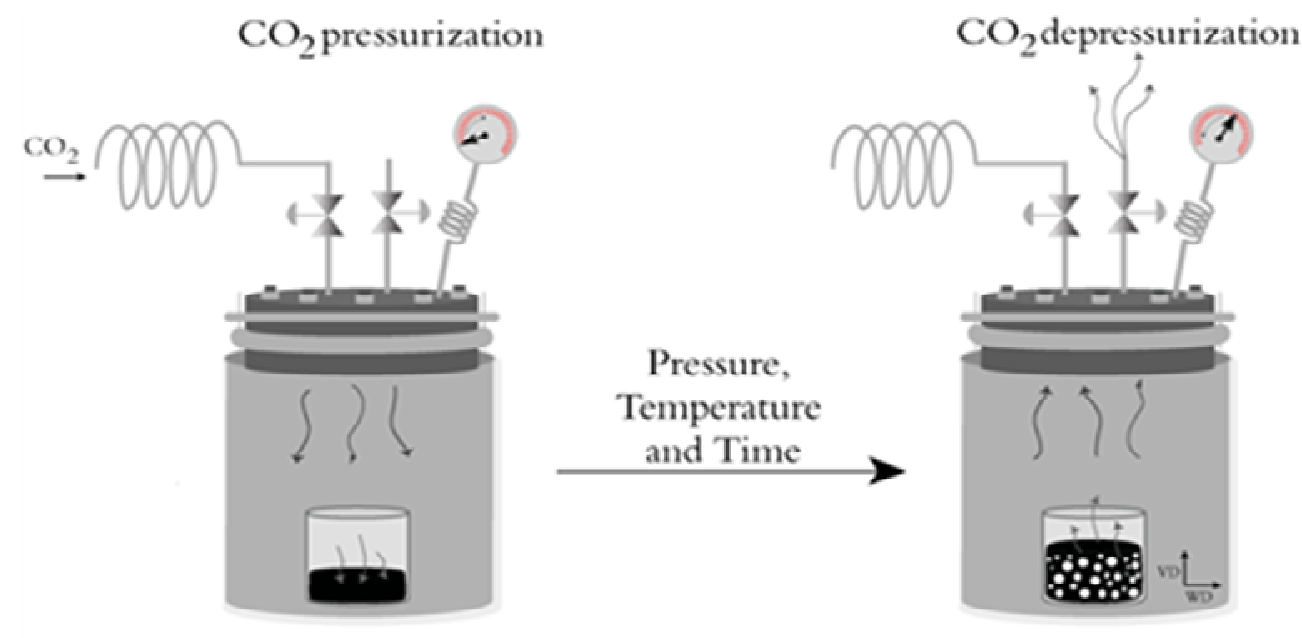

Figure 2. Scheme of the one-step batch foaming process.

\subsection{Cellular structure characterization}

The cellular structure of the foams was analyzed from scanning electron microscopy images obtained using a JEOL JSM-5610 microscope applying a voltage of $15 \mathrm{kV}$ and a working distance of $30 \mathrm{~mm}$. Samples were previously prepared by fracturing at room temperature and depositing a thin layer of gold onto their surface in argon atmosphere using a BAL-TEC SCD005 Sputter Coater.

The average cell sizes $(\phi)$ in the vertical $\left(\phi_{\mathrm{VD}}\right)$ and width $\left(\phi_{\mathrm{WD}}\right)$ foaming directions were measured using the intercept counting method [18]. The cell aspect ratio $(A R)$ was determined by dividing the value of the average cell size in the vertical direction by that measured in the horizontal one $(A R=$ $\left.\phi_{\mathrm{VD}} / \phi_{\mathrm{WD}}\right)$. The cell density $\left(N_{\mathrm{f}}\right)$ was calculated using the following equation [19]:

$$
N_{f}=\left(\frac{n}{A}\right)^{3 / 2}\left(\frac{\rho_{s}}{\rho_{f}}\right)
$$

Where $n$ is the number of cells per area, $A\left(\mathrm{~cm}^{2}\right)$, and $\rho_{\mathrm{s}}$ and $\rho_{\mathrm{f}}$ are respectively the solid and foam densities.

\section{Results and discussion}

\subsection{Desorption kinetics}

As shown in Figure 3 the maximum concentration of $\mathrm{CO}_{2}$ dissolved into PC resulted similar for both the unfilled and graphene-filled solid materials. The concentration of $\mathrm{CO}_{2}$ extrapolated to zero desorption time was respectively $42,6 \mathrm{mg} \mathrm{CO} / \mathrm{g}_{2}$ material for the neat $\mathrm{PC}$ and $43,0 \mathrm{mg} \mathrm{CO} / \mathrm{g}$ material for the graphene nanocomposite, indicating that the graphene nanoplatelets did not modify the solubility behaviour of $\mathrm{CO}_{2}$ into PC. Nevertheless, the $\mathrm{CO}_{2}$ desorption curves showed a very different trend, demonstrating an accuse effect of graphene in the desorption kinetics of $\mathrm{CO}_{2}$ out of $\mathrm{PC}$, with the graphene nanoplatelets favoring the diffusion of $\mathrm{CO}_{2}$ out of $\mathrm{PC}$ at room temperature. As a result, the calculated desorption diffusion coefficient was $6,69 \times 10^{-11} \mathrm{~m}^{2} / \mathrm{s}$ for the polycarbonate-graphene nanocomposite, considerably higher than the value of $4,45 \times 10^{-12} \mathrm{~m}^{2} / \mathrm{s}$ obtained for the neat PC. This value of the $\mathrm{CO}_{2}$ diffusion coefficient in $\mathrm{PC}$ was found to be comparable to others presented in the literature, where $D_{\mathrm{d}}$ was found to be within $2,55 \times 10^{-11}$ and $4,60 \times 10^{-12} \mathrm{~m}^{2} / \mathrm{s}$ [20] or between $1,55 \times 10^{-12}$ and $6,93 \times 10^{-12} \mathrm{~m}^{2} / \mathrm{s}$ [21]. This effect of the graphene nanoplatelets in the nanocomposite's structure might be understood as the consequence of the formation of preferential diffusion paths at the surface of the graphene platelets. 


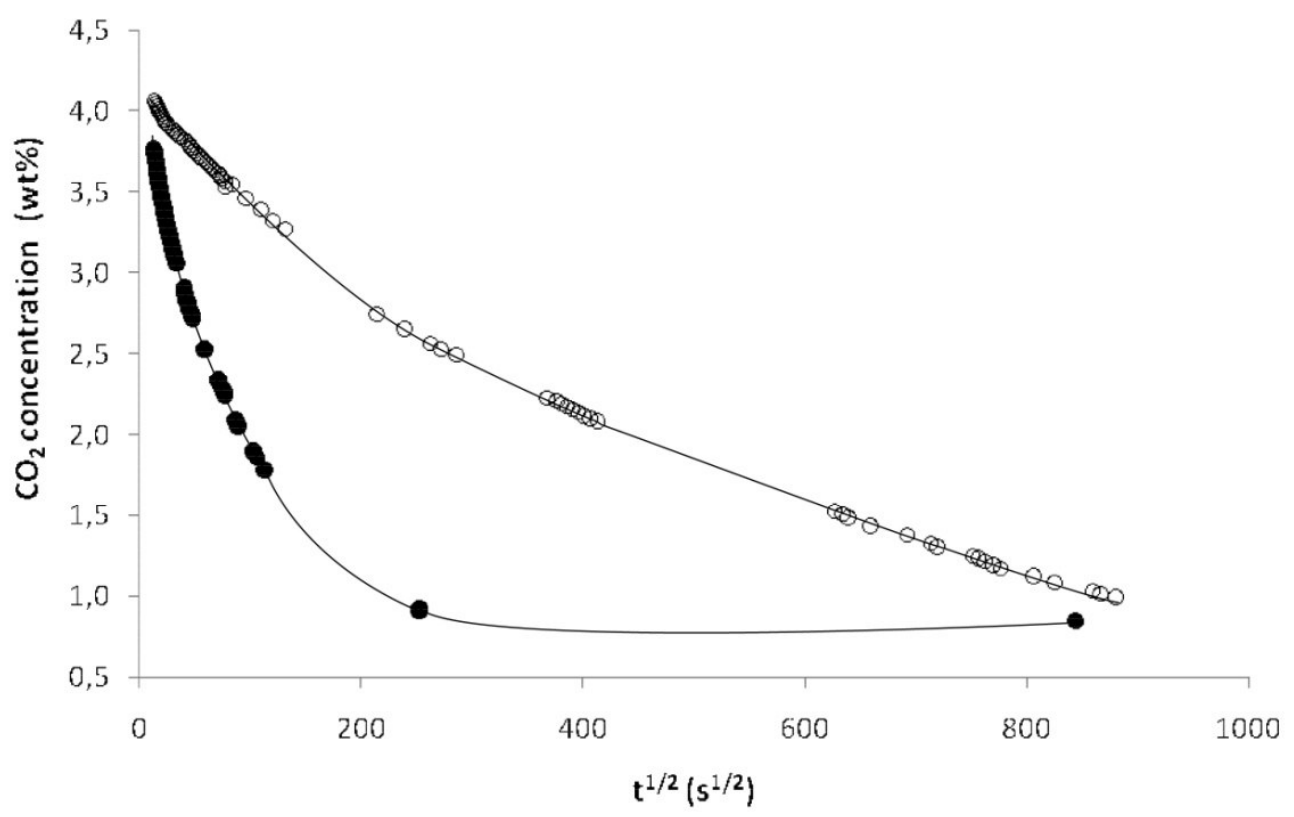

Figure 3. $\mathrm{CO}_{2}$ desorption curves for the unfilled PC (hollow symbols) and graphenefilled nanocomposite (filled symbols).

\subsection{Cellular structure}

Table 1 summarizes the values of the foaming parameters for various relative density graphene-filled nanocomposite foams and respective average cell sizes and cell aspect ratios. These values were obtained after analyzing several scanning electron micrographs at different magnifications for each foam (typical SEM micrographs are displayed in Figure 4). As can be seen, a particular cell size value was obtained for each foam at a given saturation/foaming temperature, resulting in a variation in the cell density value from $1,04 \times 10^{6}$ to $2,70 \times 10^{6}$ cells $/ \mathrm{cm}^{3}$. As expected, a characteristic homogeneous microcellular structure was obtained due to the $\mathrm{CO}_{2}$ saturation and sudden depressurization applied during foaming, with both the sudden pressure drop and graphene presence influencing the cell nucleation stage.

Table 1. Foaming process parameters and cellular characterization results of the foamed graphene-filled nanocomposites.

\begin{tabular}{|c|c|c|c|c|c|c|}
\hline $\begin{array}{l}\text { Relative } \\
\text { density }\end{array}$ & $\begin{array}{l}T_{\text {sat }}{ }^{\mathrm{a}} \\
\left({ }^{\circ} \mathrm{C}\right)\end{array}$ & $\begin{array}{c}\text { Time }^{\mathrm{b}} \\
(\mathrm{min})\end{array}$ & $\begin{array}{l}P_{\text {res }}{ }^{\mathrm{c}} \\
\text { (bar) }\end{array}$ & $\begin{array}{c}\phi_{\mathrm{VD}} \\
(\mu \mathrm{m})\end{array}$ & $\begin{array}{c}\phi_{W \mathrm{D}} \\
(\mu \mathrm{m})\end{array}$ & $A R$ \\
\hline 0,79 & 200 & 20 & 5 & 73,0 & 58,3 & 1,3 \\
\hline 0,59 & 210 & 20 & 10 & 86,2 & 97,3 & 0,9 \\
\hline 0,49 & 205 & 120 & 15 & 92,9 & 106,2 & 0,9 \\
\hline 0,47 & 205 & 40 & 20 & 94,1 & 111,3 & 0,8 \\
\hline 0,38 & 205 & 20 & 10 & 97,3 & 103,9 & 0,9 \\
\hline 0,35 & 213 & 0 & 10 & 146,6 & 143,8 & 1,0 \\
\hline
\end{tabular}

${ }^{\mathrm{a}}$ Saturation/foaming temperature.

${ }^{\mathrm{b}}$ Time at saturation/foaming temperature.

${ }^{\mathrm{c}}$ Residual pressure after depressurization. 

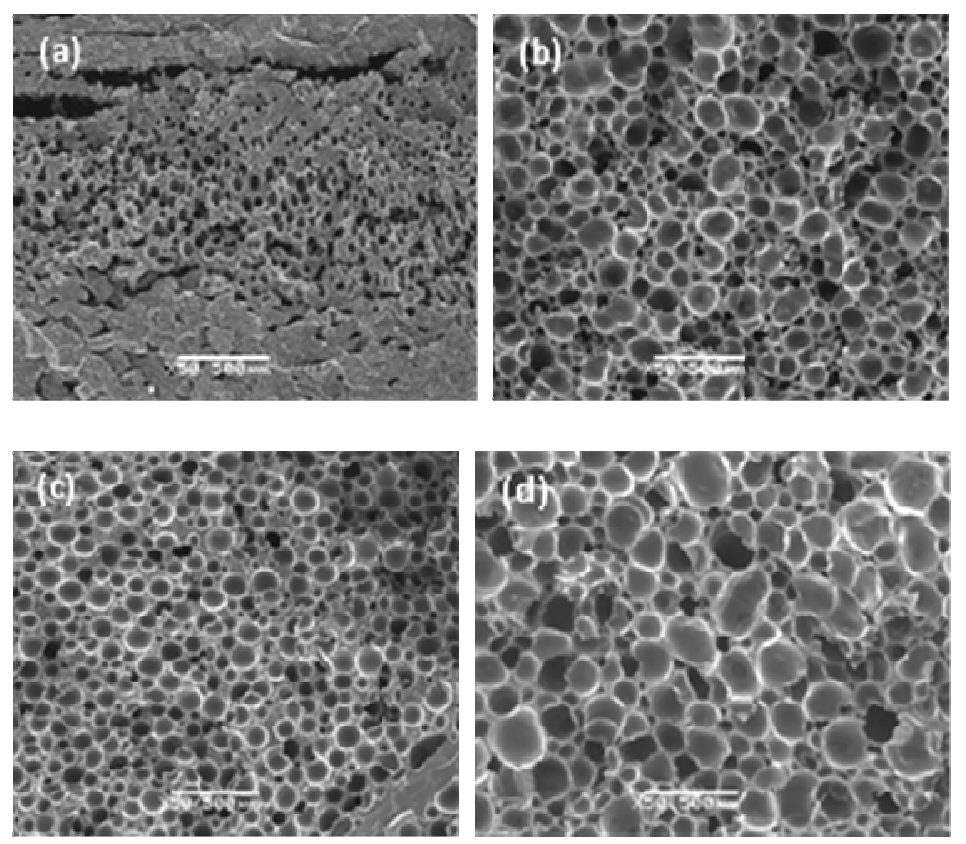

Figure 4. Typical SEM micrographs of the graphene-filled nanocomposite foams obtained at different saturation/foaming temperatures: (a) $200{ }^{\circ} \mathrm{C}$, (b) $205^{\circ} \mathrm{C}$, (c) $210{ }^{\circ} \mathrm{C}$ and (d) $213{ }^{\circ} \mathrm{C}$.

Figure 5 shows how cell size was clearly affected by the saturation/foaming temperature. Generally speaking, cell size increased from 58,3 to $146,6 \mu \mathrm{m}$ with increasing the saturation/foaming temperature from 200 to $213{ }^{\circ} \mathrm{C}$, attributed to a higher concentration of $\mathrm{CO}_{2}$ dissolved in the material. Decreasing the foaming temperature restricted cell growth and resulted in foams with higher relative densities (see Table 1). During the sudden depressurization stage, the temperature of the growing sample decreased quickly, mainly due to the adiabatic expansion of the gas, and in a minor way due to the water cooling system of the vessel. Hence, this behaviour can be explained by a faster rigidization of the softened material foamed at a lower temperature during the depressurization stage, reaching faster the glass transition temperature of the polymer than the samples foamed at higher temperatures. 


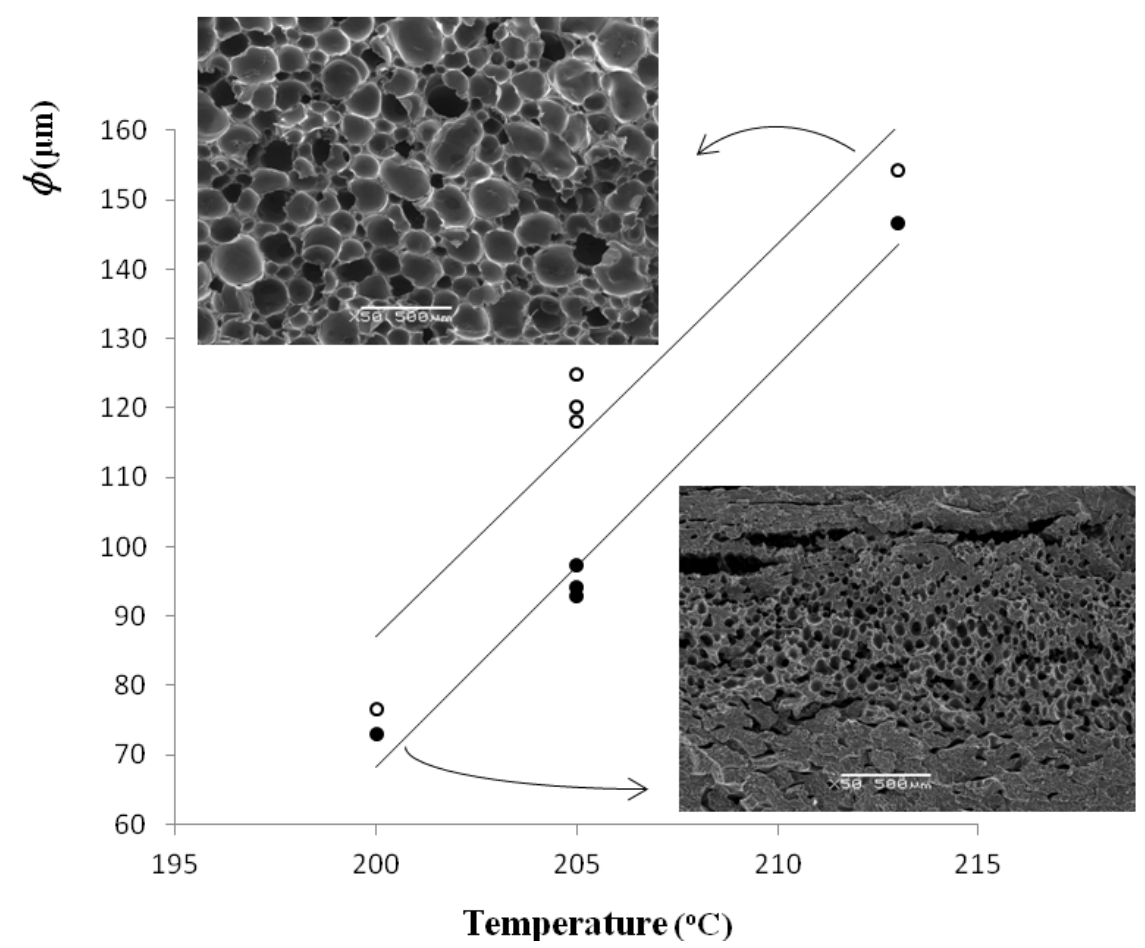

Figure 5. Influence of the saturation/foaming temperature on the average cell sizes of the graphene-filled nanocomposite foams. Hollow symbols: $\phi_{\mathrm{VD}}$; filled symbols: $\phi_{\mathrm{WD}}$

The effect of the residual pressure was found to affect the cell aspect ratio $(A R)$. Particularly, reducing the residual pressure resulted in an increment of the $A R$ (see Figure 6). A residual pressure between 10 and 15 bar was found to be the optimal residual pressure to attain perfectly spherical-like cellular structures $(A R=1)$, while a residual pressure of 5 bar resulted in a deformed cellular structure.

Finally, the observation at high magnifications of the cell walls and struts allowed identifying the presence of graphene nanoplatelets apparently well dispersed in the PC matrix (see Figure 7). 


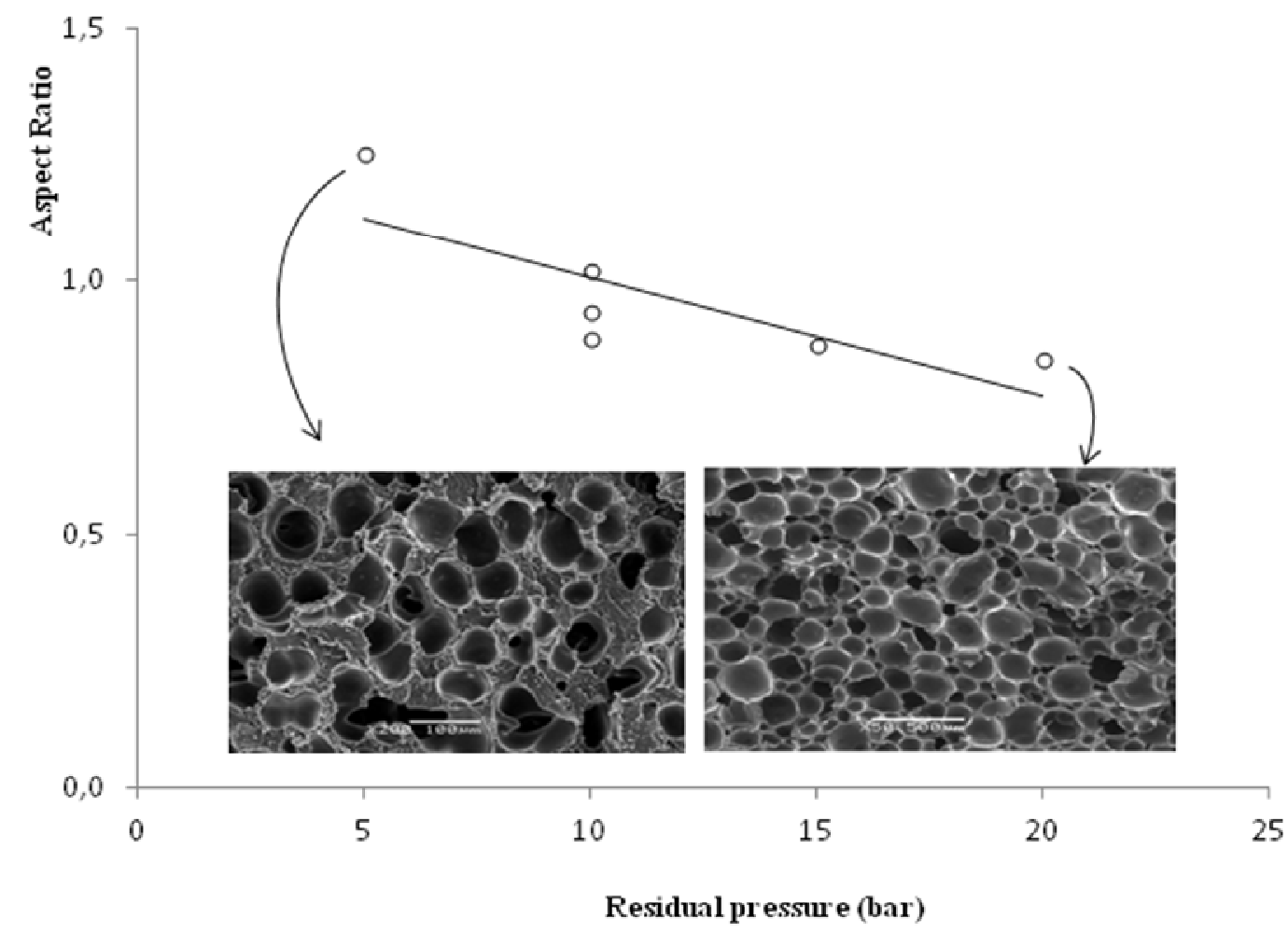

Figure 6. Influence of the residual pressure on the cell aspect ratio of the graphene-filled nanocomposite foams.

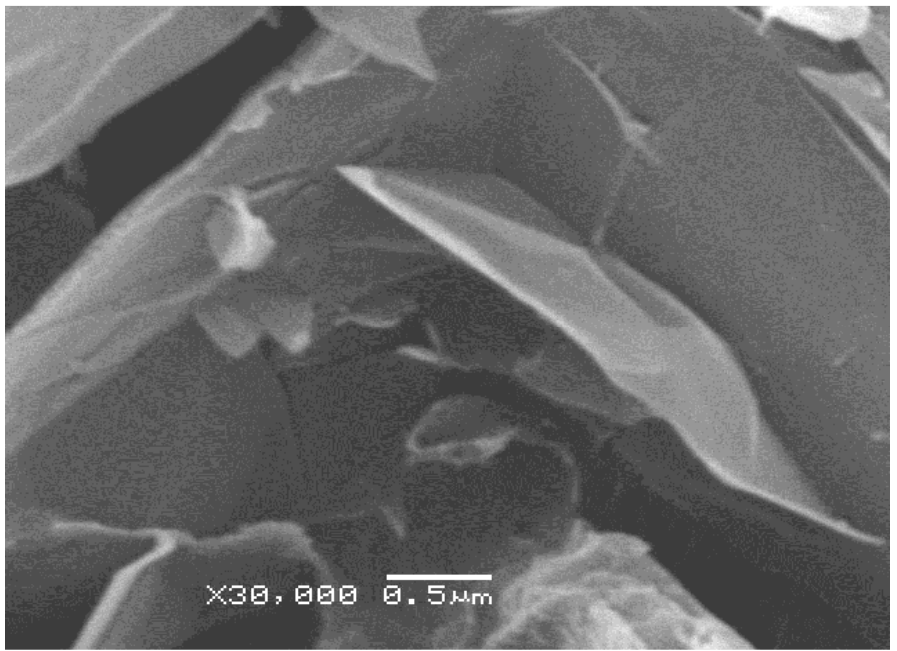

Figure 7. Detail of the graphene nanoplatelets.

\section{Conclusions}

Novel polycarbonate-graphene foams were prepared and characterized in terms of their cellular structure characteristics. The study of the desorption kinetics of $\mathrm{CO}_{2}$ out of $\mathrm{PC}$ and $\mathrm{PC}$ with $0,5 \mathrm{wt} \%$ graphene showed similar values of the maximum $\mathrm{CO}_{2}$ concentration dissolved into the material. The graphene-reinforced nanocomposite displayed a higher $\mathrm{CO}_{2}$ loss rate with a higher diffusion coefficient, related to a preferential diffusion path created at the surface of the graphene nanoplatelets, enabling a faster $\mathrm{CO}_{2}$ diffusion. 
The morphology of foams was found to be highly dependent on the saturation/foaming temperature, with foams displaying smaller cell sizes with decreasing this temperature. This was attributed to a fast cooling of the polymer, which stopped foam growth once the glass transition temperature was reached. Another foaming parameter that resulted relevant in the cellular structure was the residual pressure, which promoted the formation of cells with a uniform and regular shape until stabilization by cooling.

\section{Acknowledgments}

The authors would like to acknowledge MICINN (Government of Spain) for the financial support of project MAT2010-15565.

\section{References}

[1] Landrock A 1995 Handbook of Plastic Foams (New Jersey: Noyes) p 222

[2] Yun M and Lee W 2008 Compos. Sci. Technol. 68202

[3] Kumar V and Weller J 1994 J. Eng. Ind. 116413

[4] Antunes M, Mudarra M and Velasco J I 2011 Carbon 49708

[5] Lee L, Zeng C, Cao X, Han X, Shen J and Xu G 2005 Compos. Sci. Technol. 652344

[6] Cooper A 2000 J. Mater. Chem. 10207

[7] Goren K, Chen L, Schadler L and Ozisik R 2010 J. Supercritical Fluids 51420

[8] Yun M and Lee W 2008 Compos. Sci. Technol. 68202

[9] Wool R P 2005 Composites and Foams from Plant Oil-Based Resins (Bio-Based Polymers and Composites, London, Elsevier Science) p 114

[10] Geim A and Novoselov K 2007 Nature Materials 6183

[11] Wang F, Zhang Y, Tian C, Girit C, Zetti A, Crommie M and Shen R 2008 Science 320206

[12] Kuilla T, Bhadra S, Yao D and Kim N 2010 Prog. Polym Sci. 351350

[13] Sengupta R, Bhattacharya M, Bandyopadhyay S and Bhowmick A 2011 Prog. Polym. Sci. 36 638

[14] Beechem T and Lafdi K 2006 Carbon 441548

[15] Antunes M, Realinho V and Velasco J I 2010 J. Nanomat. Article ID 3063841

[16] Nawaby A and Zhang Z 2005 Solubility and Diffusivity in Thermoplastic Foam Processing (Thermoplastic foam processing: Principles and development, London, CRC Press) pp 1-42

[17] Crank J 1956 The Mathematics of Diffusion (London: Oxford University Press)

[18] Sims G and Khunniteekool C 1994 Cell. Polym. 13137

[19] Sorrentino L, Di Maio E and Iannace S 2010 J. Appl. Polym. Sci. 11627

[20] Tang M, Du T and Chen Y 2004 J. Supercritical Fluids 28207

[21] Tang M, Huang WH and Chen Y 20072007 J. Chin. Inst. Chem. Eng. 38419 